\title{
O debate sobre federalismo na ANPAE (2007-2018)
}

\author{
The debate on federalism in ANPAE (2007-2018) \\ El debate sobre el federalismo en ANPAE (2007-2018)
}

\author{
ELIZA BARTOLOZZI FERREIRA \\ Orcid Id: http://orcid.org/0000-0002-4100-9875 \\ Universidade Federal Do Espírito Santo \\ ANDREZA ALVES FERREIRA \\ Orcid Id: https://orcid.org/0000-0002-3149-8134 \\ Universidade Federal Do Espírito Santo
}

\begin{abstract}
Resumo: $\mathrm{O}$ artigo analisa o debate sobre federalismo nas produções da ANPAE (2007 e 2018). A política educacional é compreendida como um campo que tem suas próprias normas, valores, interesses, instituições. O software Iramuteq é utilizado como ferramenta para processar o corpus textual. A categorização temática identificou os tipos de pesquisa, as metodologias e teorias empregadas nos trabalhos. As análises dos trabalhos confirmam que a ANPAE participou ativamente do debate acadêmico do federalismo educacional, de forma a impulsionar o desenvolvimento de um subcampo.
\end{abstract}

Palavras-chave: Federalismo educacional; CAPE; Produções acadêmicas; ANPAE.

Abstract: The article analyzes the debate about federalism in ANPAE productions (2007 and 2018). Educational policy is understood as a field that has its own norms, values, interests, institutions. The Iramuteq software is used as a tool to process the textual corpus. The thematic categorization identified the types of research, methodologies, and theories employed in the works. The analyzes of the works confirm that ANPAE actively participated in the academic debate on educational federalism, in order to boost the development of a subfield.

Keywords: Educational Federalism; CAPE; Academic productions; ANPAE.

Resumen: El articulo analiza el debate sobre el federalismo en las producciones de ANPAE (2007 y 2018). La politica educativa se entiende como un campo que tiene sus propias normas, valores, intereses e instituciones. El software Iramuteq se utiliza como herramienta para procesar el corpus textual. La categorización temática identificó los tipos de investigación, metodologias y teorías empleadas en los trabajos. Los análisis de los trabajos confirman que ANPAE participó activamente en el debate académico sobre el federalismo educativo, con el fin de impulsar el desarrollo de un subcampo.

Palabras clave: Federalismo educativo; CAPE; Producciones académicas; ANPAE. 


\section{INTRODUÇÃO}

Este artigo analisa o debate sobre federalismo e políticas educacionais a partir das produções da Associação Nacional de Política e Administração da Educação (ANPAE), entre os anos de 2007 e 2018, considerando as publicações dos Encontros/Simpósios Nacionais e Internacionais e da Revista Brasileira de Política e Administração da Educação (RBPAE) como objeto empírico, ou seja, o próprio campo como objeto de estudo. Objetivamos responder como ocorreu o debate sobre o federalismo no Campo Acadêmico da Política Educacional (CAPE), em especial na ANPAE. Argumentamos que a emergência dos estudos sobre o federalismo educacional se deu no contexto dos debates em torno do Plano Nacional de Educação (PNE). A investigação aqui desenvolvida revela que a centralidade nas pesquisas sobre federalismo educacional no Campo da Política Educacional (CAPE) pode levar a entender que temos a criação de um subcampo.

Justifica-se investigar a ANPAE pelo fato de ser uma entidade representativa da produção acadêmica nacional sobre o tema, sendo um agente, cuja atuação tem sido de grande relevância em contextos caracterizados por disputas em torno do direito à educação. Especialmente, destacamos o seu forte protagonismo no processo de elaboração e aprovação do PNE (BRASIL, 2014), contexto em que situamos a emergência do subcampo Federalismo Educacional.

Este artigo está organizado em três seções, além desta introdução, que apresenta os objetivos e justifica a escolha pela análise da produção acadêmica da ANPAE, e das considerações finais. Sem pretender uma abordagem que dissocia o referencial teórico-metodológico da análise dos dados, a primeira parte aborda de forma sumária alguns conceitos da teoria social de Bourdieu que embasam esta pesquisa, bem como os procedimentos metodológicos utilizados para processamento e análise dos dados. A segunda seção discorre sobre o Federalismo Educacional e a ideia de subcampo do CAPE. Na terceira seção, analisamos a produção selecionada para esta investigação por meio de categorias temáticas identificadas a partir do software Iramuteq e por nós classificada e interpretada.

\section{ASPECTOS TEÓRICOS-METODOLÓGICOS}

Este artigo parte da perspectiva da ciência como construção social e como uma das diversas manifestações para a elaboração do conhecimento, sendo compreendida como um campo (BOURDIEU, 2004). O campo científico é "o universo no qual estão inseridos os agentes e as instituições que produzem, reproduzem, ou difundem [...] a ciência" (BOURDIEU, 2004, p.20). Cabe ressaltar que esse campo é regido por leis próprias e que seus agentes e instituições se 
relacionam com outros campos sociais, a partir do que sofre pressões externas. Para Bourdieu (2004), a construção do conhecimento científico acontece por meio de um diálogo contínuo entre fatores externos (fatos históricos, econômicos e sociais), juntamente com as leis internas inerentes ao campo científico.

A partir da noção de campo de Pierre Bourdieu, adotamos a perspectiva de que o CAPE é um espaço estruturado de relações de força, no qual os agentes disputam os capitais específicos que se apresentam no jogo (BOURDIEU, 2004). O CAPE, no Brasil, vem se consolidando como campo acadêmico dotado de autonomia relativa aos demais campos em razão de sua estruturação em torno de leis específicas. Assim como os demais campos, o CAPE tem suas próprias normas, valores, interesses, instituições, órgãos de divulgação, instâncias de consagração, hierarquias de legitimidade e critérios de divisão social.

Compreende-se que essas propriedades de um campo acadêmico ainda estão para serem experienciadas e investigadas na Política Educacional, uma vez que se trata de um campo em expansão e ainda em construção (STREMEL, 2016). Este trabalho busca contribuir com essa construção.

Argumenta-se, a partir desta visão, que a Política Educacional constitui um campo próprio situado no campo mais amplo da educação. Esse campo, contudo, assim como o seu macrocosmo, não possui um único núcleo teórico pertencente à política educacional, mas a vários núcleos teóricos. Ele se constitui, assim, um campo multidisciplinar, cuja complexidade interdisciplinar se manifesta na diversidade de epistemologias empregadas no desenvolvimento da pesquisa em política educacional (TELLO, 2019).

\subsection{O FEDERALISMO E O CAMPO DAS POLÍTICAS PÚBLICAS}

A multidisciplinaridade é também uma característica do campo das políticas públicas. Esse campo caracteriza-se historicamente como um contexto em que as ciências sociais foram convocadas a contribuírem com os estudos acerca dos processos de governo e a considerarem os problemas do Estado com maior rigor (OLIVEIRA, 2011, SOUZA, 2006). Esse contexto favoreceu tanto a emergência de um novo campo - policy science - quanto a sua autonomização.

De igual modo, o campo do federalismo não apenas se apresenta como uma relevante agenda de pesquisa nas ciências sociais como também envolve um campo teórico vasto com história intelectual própria (SOUZA, 2008; LOTTA, 2015). No Brasil, de acordo com o estudo realizado por Sudano, Soares e Vergili (2015), a produção acadêmica sobre as políticas públicas vem sendo dominada 
por abordagens teóricas advindas do campo do federalismo, principalmente no final dos anos 1990, caracterizado por um período de democratização política e social do País.

Nesta investigação, o princípio que sustenta a nossa concepção de federalismo refere-se à pactuação de sujeitos coletivos que mantém suas particularidades (sociais, étnicas, religiosas), com vistas à articulação de um coletivo mais amplo, o Estado Federal. Amparados por esse princípio, compreendemos que o federalismo, como uma forma de organização do Estado, implica a divisão territorial do poder, a articulação do poder central com os poderes regional e local, configurando-se como "um conjunto de complexas alianças, que buscam a compatibilização de valores e interesses entre atores políticos (AFFONSO; BARROS; SILVA, 1995, p. 57)". No Brasil, considerando o federalismo de base cooperativa adotado pela Constituição Federal de 1988 (CF/88), essa articulação é concebida como imprescindível. Esse modelo ampara-se na cooperação entre os entes federados na provisão das políticas sociais para a garantia dos direitos sociais.

Não obstante as diferentes perspectivas teóricas que vêm sendo adotadas nos estudos sobre o federalismo brasileiro, há um crescente movimento de adesão entre os pesquisadores ao pressuposto de que o federalismo se constitui uma variável fulcral para análise das políticas públicas, pois interfere tanto no funcionamento quanto em seus resultados. Esse pressuposto, conforme será abordado neste trabalho, foi também incorporado pelos pesquisadores do CAPE.

Nesse sentido, argumentamos que as teorias do federalismo vêm sendo também incorporadas ao habitus do CAPE, a partir de uma composição com as abordagens sobre o Estado, até então predominantes no campo (SOARES, 2019). Essa incorporação ocorreu, sobretudo, motivada por um contexto de produção teórica, cujos enfoques conferiram um papel cada vez mais autônomo e central para as instituições políticas como fontes explicativas (AVRITZER; MILANI; BRAGA, 2016). Esses estudos pressupõem que "as instituições têm efeitos discerníveis e relevantes na vida política, influindo sobre as decisões dos atores e sobre os resultados de suas ações (ALMEIDA, 2001, p. 13)". Em relação ao campo científico, Bourdieu ressalta que, assim como os outros campos, o babitus é "o lugar de lógicas práticas, mas com a diferença de o habitus científico ser uma teoria realizada, incorporada (BOURDIEU, 1996, p.61; grifos nossos)".

Assim, a disseminação do pressuposto de que o federalismo é uma instituição e, portanto, uma fonte explicativa dos fenômenos políticos, justifica, em grande medida, a sua relevância para o campo das políticas públicas. Dessa 
forma, como capital científico, produz efeitos simbólicos, visto que obtém um "reconhecimento explícito ou prático, o de habitus estruturado segundo as mesmas estruturas do espaço em que foi engendrado" (BOURDIEU, 2001, p. 296).

Tendo em vista a força e a predominância da produção sobre o federalismo educacional na ANPAE, podemos afirmar que esse tema constituiu um habitus na entidade, pois a ANPAE é um agente do CAPE que exerce controle sobre o capital científico, a produção e divulgação do conhecimento em política educacional, bem como “[...] dos objetos dignos de interesse, interessantes, importantes, capazes, portanto, de merecer investimento (BOURDIEU, 2004, p. 30)".

\subsection{ASPECTOS METODOLÓGICOS}

Não delimitamos um corpus de análise a priori, pois, um dos nossos objetivos era o de identificar em que momento o federalismo passa a ser um objeto de interesse da ANPAE. Para tanto, foram pesquisadas todas as edições e artigos publicados anteriores à versão digital da RBPAE, referentes ao período de 1983 a 2005, digitalizadas e disponíveis em sua página na internet. A partir de 2006, com a versão digital da $\mathrm{RBPAE}^{1}$, a pesquisa foi realizada por meio de busca no site da mesma, com os descritores: "Federalismo", "Federação", "pacto federativo", "Relações Intergovernamentais", "Cooperação federativa"; "Colaboração federativa"; "Coordenação federativa"; "Regime de Colaboração". As publicações em anais dos Simpósios Nacionais e Congressos Internacionais foram disponibilizadas na página da ANPAE a partir do ano de 2007, o que nos possibilitou examiná-las em sua versão digital bem como utilizar os referidos descritores na pesquisa ${ }^{2}$.

\subsubsection{PROCESSAMENTO E ANÁLISE DOS TEXTOS}

Os dados foram processados pelo software IRAMUTEQ (Interface de $\mathrm{R}$ pour les Analyses Multidimensionnelles de Textes et de Questionnaires), que tem por finalidade descobrir a informação essencial contida em um texto, através de

\footnotetext{
1 A Revista Brasileira de Administração da Educação (RBAE) foi criada em 1983 e, a partir de 1997, amplia seu foco e escopo passando a denominar-se RBPAE.

2 Em virtude de limitações editoriais, não foi possível incluir na listagem de referências deste artigo a indicação bibliográfica dos 82 trabalhos analisados; essa, contudo, pode ser consultada no banco de dados da pesquisa das autoras, disponível no Núcleo de Estudos de Políticas Educacionais (NEPE).
} 
análise estatística textual. Neste artigo, utilizaremos a Análise de Similitude ${ }^{3}$ e a Classificação via método Reinert ${ }^{4}$. Este software dispõe de ferramentas para análise de conteúdo dos termos ou formas mais recorrentes dentro do corpus textual ${ }^{5}$, o que possibilita a análise qualitativa a partir dos dados gerados.

\section{Quadro 1 - Síntese da coleta e análise dos dados}

\begin{tabular}{|c|c|c|c|}
\hline $\begin{array}{c}\text { LOCAL DA } \\
\text { PUBLICAÇÃO }\end{array}$ & PERÍODO & FERRAMENTAS DE BUSCA & FERRAMENTA DE ANÁLISE \\
\hline $\begin{array}{c}\text { RBAE } \\
\text { RBPAE }\end{array}$ & 1983 a 2005 & $\begin{array}{c}\text { Download dos arquivos digitalizados } \\
\text { disponíveis na página da Revista }\end{array}$ & $\begin{array}{c}\text { Leitura e análise manual de conteúdo } \\
\text { dos textos digitalizados }\end{array}$ \\
\cline { 2 - 4 } & 2006 a 2018 & $\begin{array}{c}\text { Busca no portal da Revista por meio de } \\
\text { descritores }\end{array}$ & Software IRAMUTEQ \\
\hline $\begin{array}{c}\text { Anais dos Eventos: } \\
\text { Congressos, Simpósios e } \\
\text { Colóquios }\end{array}$ & 2007 a 2018 & $\begin{array}{c}\text { Busca na página da ANPAE por meio de } \\
\text { descritores, em CD- Rom e/ou coletâneas }\end{array}$ & Software IRAMUTEQ \\
\hline
\end{tabular}

Fonte: Elaboração das autoras, 2019.

A análise de conteúdo dos textos foi baseada em Bardin (2011) e desenvolvida por meio da classificação desses trabalhos em quatro categorias temáticas indicadas na seção 3 .

\section{A EMERGÊENCIA DO FEDERALISMO NO CAPE}

Com base no pressuposto de que a Política Educacional brasileira se constitui um campo acadêmico específico, utilizamos o termo subcampo ${ }^{6}$ para nos referir ao Federalismo Educacional como um subcampo do CAPE. A emergência desse subcampo ocorre no contexto de implantação e debate dos planos nacional e subnacionais de educação. O destaque dado a esse tema tem relação com a atuação dos governos vinculados ao Partido dos Trabalhadores (2003-2016),

3 O grafo representa a ligação entre palavras do corpus textual, sendo possível inferir a estrutura de construção do texto e os temas de relativa importância, a partir da concorrência entre as palavras.

4 Nessa análise, os segmentos de texto são classificados de acordo com seu respectivo vocabulário e o conjunto de termos é particionado de acordo com a frequência das raízes das palavras. A lógica de correlação utiliza as segmentações do corpus textual, juntamente com a lista de formas reduzidas e o dicionário embutido para apresentar um esquema hierárquico de classes. (OLIVEIRA, 2015).

$5 \quad$ O corpus geral foi constituído por 82 textos, separados em 331 segmentos de texto (ST), com aproveitamento de 248 ST's (74,92\%). Emergiram 11.746 ocorrências (palavras, formas ou vocábulos), categorizado em quatro classes: classe 1 , com ST (31,9\%), classe 2, com ST (23,8\%), classe 3, com ST $(29,8 \%)$, classe 4, com ST $(14,5 \%)$.

6 Embora Bourdieu (2004) admita a existência de subcampos, raramente utiliza o termo, preferindo a expressão "campo" para se referir, a rigor, àquilo que seriam os subcampos do campo cultural, como por exemplo, os (sub) campos da moda, o literário, o científico, o religioso etc. 
em que o planejamento foi retomado como estratégia para o desenvolvimento do país, incluindo aí não somente a educação como também as demais políticas sociais.

É importante, contudo, assinalar que este período também foi marcado por muitas ambiguidades, visto que se procurou conciliar os interesses do capital financeiro aos da classe trabalhadora e das camadas sociais mais pobres da população brasileira. Porém, ao contrário dos governos anteriores que reputaram à liberalização, à privatização e à desregulamentação dos mercados o papel de condução e de dinamismo da economia, cujo resultado foi, dentre outros, o baixo crescimento econômico. os governos do PT atuaram no sentido de reafirmar a soberania nacional (POCHMANN, 2017).

\subsection{O FEDERALISMO NO PERÍODO DE 1983 A 2005: UM DESCONHECIDO?}

A análise de conteúdo e de indexação dos textos publicados pela ANPAE entre 1983 a 2005 não permite afirmar relevância e/ou aprofundamento conceitual e teórico sobre o tema do federalismo educacional. Nesse período, foi possível identificar os temas mais recorrentes, agrupados da seguinte forma: 1) centralização/descentralização - democratização, a autonomia/poder local e municipalização; 2) financiamento - políticas de fundo, competências das esferas administrativas no provimento do direito à educação; 3) relação entre municípios, estados e União, entre sistemas de ensino; 4) sistemas - estaduais, municipais, a criação/constituição do Sistema Nacional de Educação (SNE); 5) Planejamento e gestão - gestão democrática, qualidade da oferta educacional, reformas; 6) questões estruturais - desigualdades entre regiões, estados e municípios. Houve algumas poucas aparições dos termos federalismo e federação no interior dos textos. O primeiro foi referido como um sistema descentralizado de governo (SANDER, 1988); o segundo como uma forma de organização do Estado (BOAVENTURA, 1993).

Portanto, observamos uma tímida referência direta ao federalismo, mas isso não significa que as questões emergentes na última década (sobretudo a partir de 2010), pelas lentes do federalismo, não constavam das investigações e preocupações dos autores naquele período. Isto porque, em grande medida, como afirmam alguns pesquisadores, existe uma articulação entre a agenda de pesquisas do CAPE e a própria agenda da política educacional (SOUZA, 2014; KRAWCZYK, 2012). Prova disso é que as questões apontadas nas publicações 
desse período (1983-2005) serão articuladas ao debate sobre o federalismo no CAPE a partir de meados da primeira década dos anos 2000, fortemente influenciadas pelo contexto social, político e econômico mais amplo.

\subsection{O CONTEXTO DE EMERGÊNCIA DO FEDERALISMO EDUCACIONAL}

Nas ultimas três décadas, foram introduzidas mudanças que afetaram a gestão dos sistemas educativos no Brasil em suas variadas dimensões, em especial, no financiamento, avaliação e planejamento. Essas alterações ocorreram a partir da CF/88, por meio de suas Emendas Constitucionais (EC), com a promulgação da nova Lei de Diretrizes e Bases da Educação Brasileira (LDB - 9.394/96) (BRASIL, 1996) ${ }^{7}$ e pelas demais leis e decretos. Essas modificações terão rebatimentos no contexto de formulação do novo PNE (BRASIL, 2014), de modo a tensionar o debate do federalismo educacional, dando-lhe centralidade na agenda política e acadêmica.

Importante observar que o primeiro PNE (2001-2011) inscreveu o federalismo "autêntico" em matéria educativa, a partir da perspectiva da divisão de responsabilidades sob a premissa do "aprimoramento do regime de colaboração", com efeito de soma zero. No que concerne ao financiamento, foi editada a EC no 14/1996, que cria o Fundo de Manutenção e Desenvolvimento do Ensino Fundamental e de Valorização do Magistério (FUNDEF) como uma tentativa de enfrentar o problema da desigualdade de alocação de recursos entre os entes federados. Esse fundo foi substituído pelo Fundo de Manutenção e Desenvolvimento da Educação Básica e de Valorização dos Profissionais da Educação (FUNDEB), com a aprovação da EC 53/2006, que ampliou o financiamento para todas as etapas e modalidades da educação básica.

Com relação ao planejamento, a partir da EC no 59/2009, ocorreu a modificação do artigo 214, determinando que a lei devesse estabelecer o PNE com o objetivo de articular o SNE, em Regime de Colaboração. Essa emenda introduziu ainda, o $\ 4^{\circ}$ no artigo 211 , prescrevendo que, na organização de seus sistemas de ensino, os entes federados definissem "formas de colaboração", de modo a garantir a universalização do ensino obrigatório.

Ainda na dimensão do planejamento, foi criado o Plano de Desenvolvimento da Educação (PDE) pelo Decreto n. 6.094/2007. De acordo com o disposto nesse Decreto, o PDE buscou introduzir mecanismos de planejamento

\footnotetext{
7

Não serão aqui expostos os conteúdos específicos contidos nos textos da CF/88 e da LDB/9394/96 que repercutem diretamente na questão federativa, em razão da limitação do espaço, mas também por considerar que eles serão contemplados nas discussões dos trabalhos analisados.
} 
entre os entes federados, por meio do Plano de Ações Articuladas (PAR), bem como definiu um índice de aferição da qualidade, o Índice de Desenvolvimento da Educação Básica (IDEB). O PAR, de acordo com Ferreira (2014), pretendeu ser um mecanismo de estabelecimento do Regime de Colaboração entre os entes federativos com o objetivo de viabilizar a autonomia institucional e a qualidade da educação brasileira.

Em 2012, no âmbito do Ministério da Educação, com o objetivo de articular os sistemas de ensino e viabilizar a instituição do SNE em Regime de Colaboração, foi também criada a Secretaria de Articulação com os Sistemas de Ensino (SASE).

O fortalecimento do debate em torno da necessária instituição e consolidação de um SNE se deu com a realização de três Conferências Nacionais de Educação (2008, 2010 e 2014), seguidas das estaduais e municipais (2009 e 2013), por meio de uma ampla mobilização social face às discussões sobre a educação no contexto do federalismo brasileiro.

Como expressão das questões colocadas como prioritárias para a agenda educacional do período, em 2008, a Conferência Nacional de Educação Básica (CONEB) incorporou em seu objetivo contribuir para a organização de "um Sistema Nacional Articulado de Educação, como consequência de um Regime de Colaboração" (BRASIL, 2008). Assim, a constituição do SNE e a regulamentação do Regime de Colaboração são colocados como as principais bandeiras da política educacional, temas que serão retomados nas CONAE de 2010 e 2014.

No campo acadêmico, destacam-se alguns eventos promovidos pelas principais associações científicas da educação no ano de 2013: O CEDES promoveu o IV Seminário da Educação Brasileira com o tema "O PNE em foco: políticas de responsabilização e Sistema Nacional de Educação”. A ANPEd, em sua $36^{a}$ Reunião Nacional, adotou o tema: "Sistema Nacional de Educação e Participação Popular: desafios para as políticas educacionais".

Do exposto, observa-se que os temas e subtemas das CONAE foram articulados aos principais conceitos vinculados ao campo teórico do federalismo, quais sejam: a cooperação, colaboração, coordenação e articulação federativa, o pacto federativo $e$ as relaçoes intergovernamentais, além da autonomia, pressuposto desse sistema.

Apesar de as primeiras publicações sobre o federalismo ocorrerem inclusive nestes eventos ainda em meados dos anos $2000^{8}$, a maior parte dos trabalhos publicados especialmente nesses eventos ocorreu a partir do ano de 2013. Destaca-se ainda, a presença da temática em artigos tanto de periódicos 
ligados a estas Associações (RBPAE, RBE e Educação \& Sociedade) como também em outros ${ }^{9}$, inclusive com números dedicados exclusivamente a ela.

A análise da produção da ANPAE $^{10}$ indica que, nas investigações realizadas no período, os objetos de pesquisa que conformam o $\mathrm{CAPE}^{11}$ serão abordados a partir dos conceitos envolvidos nas teorias do federalismo, aos quais se destacam: os sistemas de ensino, os diversos programas, os planos, as modalidades da educação básica, o financiamento, a avaliação, o trabalho docente, a formação e carreira docente, a qualidade, a descentralização, a autonomia, a participação, a gestão democrática, o direito à educação, os conselhos e fóruns de participação social e política. Essa abrangência assinala a grande capilaridade que o federalismo vai alcançar no CAPE, bem como indica a constituição de um novo subcampo de estudos - "o Federalismo Educacional".

\section{O DEBATE SOBRE FEDERALISMO EDUCACIONAL NA ANPAE}

Conforme exposto no item anterior, a agenda da política para a educação nos anos 2000 foi fortemente mobilizada pelo debate do novo PNE. A atuação da ANPAE refletiu essa agenda por meio de diversas frentes, tais como: a realização de eventos; a participação de seus associados em audiências, conferências, grupos de trabalho, palestras, mesas redondas, ocorridas em outras instituições ligadas aos governos e à sociedade civil; e de suas publicações em coletâneas, anais dos eventos, artigos de sua revista, dentre outras manifestações escritas e exibidas em sua página na internet.

$\mathrm{Na}$ pesquisa, identificamos que os primeiros trabalhos relacionados ao tema do federalismo ocorreram ainda no ano de 2007 por meio das discussões sobre o Regime de Colaboração tanto na modalidade comunicação oral, como painel, por ocasião do XXIV Simpósio na cidade de Porto Alegre ${ }^{12}$ e, ainda, em 2008 na RBPAE. Todavia, somente em 2009, o federalismo será explicitado nos títulos de dois trabalhos publicados na modalidade comunicação oral, no

9 A Revista Retratos da Escola publicou um número em 2012 (10, vl. 06) dedicado ao tema: Federalismo e Educação; a Revista Educação \& Sociedade, em 2013 publicou dois números contendo artigos voltados à temática: o n. 124 V. 34 (Jul/Set 2013) - Desafios à Educação Brasileira: Pne, Responsabilização, Colaboração e Sistema Nacional de Educação e o N. 125 V.34 (Set/Dez 2013) - Sociedade, Estado e Educação ou da Construção do Sistema Nacional da Educação.

10 Identificamos que outras entidades e associações, como o CEDES e a ANPEd e CNTE também realizaram eventos sobre tema, publicando em seus anais e periódicos.

11 Estes objetos são identificados na pesquisa realizada por Silva e Jacomini (2016) e também reiterados na tese de Soares (2019) como sendo os principais temas abordados pelo CAPE.

12 Painel 06 - "Regime de colaboração, autonomia e gestão local da educação".

458 - RBPAE - v. 36, n. 2, p. 449 - 472, mai./ago. 2020 
XXV Simpósio. Esse Simpósio contou com a Mesa Redonda "Sistema Nacional de Educação: políticas de Estado"e Regime de Colaboração". O que também ocorreu em 2013, no XXVII Simpósio da ANPAE "Políticas, planos e gestão da educação: democratização e qualidade social" com a mesa redonda "Federalismo e gestão da educação".

Em 2015, a ANPAE criou o Eixo 04 - "Planejamento da Educação, cooperação federativa e Regime de Colaboração entre sistemas na educação". Esse eixo, além de explicitar o termo "federalismo", contempla os subtemas e/ou objetos relacionados diretamente com o federalismo presentes nas produções do campo naquele período. Além do eixo, algumas mesas redondas foram realizadas nesse mesmo ano: Mesa Redonda 20 - Tema - O Regime de Colaboração, o federalismo brasileiro e o Sistema Nacional de Educaşão; Mesa Redonda 25 - Cooperação Federativa e Regime de Colaboração entre Sistemas na Educação.

Em 2016, a ANPAE publicou Coletâneas e Cadernos Temáticos com o objetivo de congregar resultados de estudos e pesquisas sobre os seguintes temas: relações federativas e Sistema Nacional de Educação, planos de educação, qualidade social da educação básica, política nacional de formação e valorização dos profissionais da educação, Regime de Colaboração, gestão democrática da educação e financiamento da educação (ANPAE, 2016).

\subsection{PRODUÇÕES DA ANPAE (2007-2018)}

Conforme arrolados no quadro a seguir, foram localizados 69 trabalhos dentro da modalidade anais dos eventos (Congressos e Simpósios) e 13 artigos na RBPAE.

\section{Quadro 2 - Síntese da Pesquisa.}

\begin{tabular}{|c|c|c|c|}
\hline Veículo & Período & Edições & Trabalhos localizados \\
\hline \multirow{9}{*}{ RBPAE } & \multirow{9}{*}{$2006-2018$} & $2008-v .24$, n. 3 & 1 \\
\hline & & $2009-v .25$, n. 1 & 1 \\
\hline & & $2010-$ v. 26, n.1 e 3 & 2 \\
\hline & & $2012-v .28, n .2$ & 1 \\
\hline & & $2014-v .30, n .2$ & 1 \\
\hline & & $2015-v .31, n .2$ & 1 \\
\hline & & $2016-$ v.32, n.1 & 1 \\
\hline & & $2017-v .33$, n.1, 2 & 3 \\
\hline & & $2018-$ V.34, N.3 & 1 \\
\hline \multicolumn{3}{|c|}{ SUBTOTAL } & 13 \\
\hline
\end{tabular}




\section{Quadro 2 - Síntese da Pesquisa.}

\begin{tabular}{|c|c|c|c|}
\hline Veículo & Período & Edições & Trabalhos localizados \\
\hline \multirow{11}{*}{ Eventos } & \multirow{11}{*}{$2007-2018$} & $\begin{array}{l}2007 \text { - XXIII Simpósio, V Congresso Luso-Brasileiro e } \\
\text { o Colóquio Ibero-Americano de Política e Administração }\end{array}$ & 3 \\
\hline & & $\begin{array}{c}2009 \text { - XXIV Simpósio, III Congresso Interamericano } \\
\text { de Política e Administração }\end{array}$ & 3 \\
\hline & & $\begin{array}{c}2010 \text { - I Congresso Ibero Brasileiro, VI Congresso Luso } \\
\text { brasileiro }\end{array}$ & 1 \\
\hline & & $\begin{array}{l}2011 \text { - XXV Simpósio, } 2^{\circ} \text { Congresso Ibero-Americano } \\
\text { de Política e Administração da Educação }\end{array}$ & 7 \\
\hline & & 2012 - III Congresso Ibero Americano & 5 \\
\hline & & $\begin{array}{l}2013 \text { - XXVI Simpósio Brasileiro de Política e } \\
\text { Administração da Educação }\end{array}$ & 7 \\
\hline & & $\begin{array}{c}2014 \text { - IV Congresso Ibero-Americano / VII Congresso } \\
\text { Luso Brasileiro }\end{array}$ & 8 \\
\hline & & $\begin{array}{c}2015 \text { - XXVII Simpósio Brasileiro de Política e } \\
\text { Administração da Educação }\end{array}$ & 13 \\
\hline & & $\begin{array}{c}2016 \text { - V Congresso Ibero americano; VIII Congresso } \\
\text { Luso brasileiro }\end{array}$ & 8 \\
\hline & & $\begin{array}{l}2017 \text { - XXVIII Simpósio Brasileiro de Política e } \\
\text { Administração da Educação }\end{array}$ & 8 \\
\hline & & $\begin{array}{c}2018 \text { - VI Congresso Ibero-Americano IX Congresso } \\
\text { Luso-Brasileiro }\end{array}$ & 6 \\
\hline \multicolumn{3}{|r|}{ SUBTOTAL } & 69 \\
\hline \multicolumn{3}{|r|}{ TOTAL } & 82 \\
\hline
\end{tabular}

Fonte: Elaboração das autoras, 2019.

A maioria dos trabalhos sobre o tema ocorre a partir do ano de 2010, como pode ser observado no quadro 2. No ano de 2015, foram publicados 14 trabalhos, o que pode ser explicado pela criação de um eixo específico (Eixo 04 - Planejamento da Educação, cooperação federativa e Regime de Colaboração entre sistemas na educação). Mas também pelo aumento da produção de teses e dissertações sobre o tema. Os resultados (totais ou parciais) dessas pesquisas (concluídas ou em construção) são, em geral, apresentados nestes eventos e/ou publicados em $\operatorname{artigos}^{13}$.

Dos 69 trabalhos apresentados na modalidade eventos, 3 foram apresentados ainda no ano de 2007, tomando o Regime de Colaboração como objeto. Essa categoria será incorporada à maioria dos trabalhos analisados, indicando sua centralidade neste subcampo, seja como objeto central, seja como um conceito importante das pesquisas. 


\subsubsection{A MATRIZ DO FEDERALISMO EDUCACIONAL: O REGIME DE COLABORAÇÃO}

A centralidade do Regime de Colaboração no debate sobre o federalismo educacional pode ser observada na representação gráfica a seguir. Observase ainda, nessa representação, a recorrência de outros conceitos também importantes e relacionados ao Regime de Colaboração: pacto federativo, relações intergovernamentais, coordenação e cooperação federativa. Será, portanto, a partir da compreensão desses conceitos que ocorrerão os principais debates no subcampo federalismo educacional.

Análise de similitude 1 - Total dos resumos e palavras-chave (2007-2018)

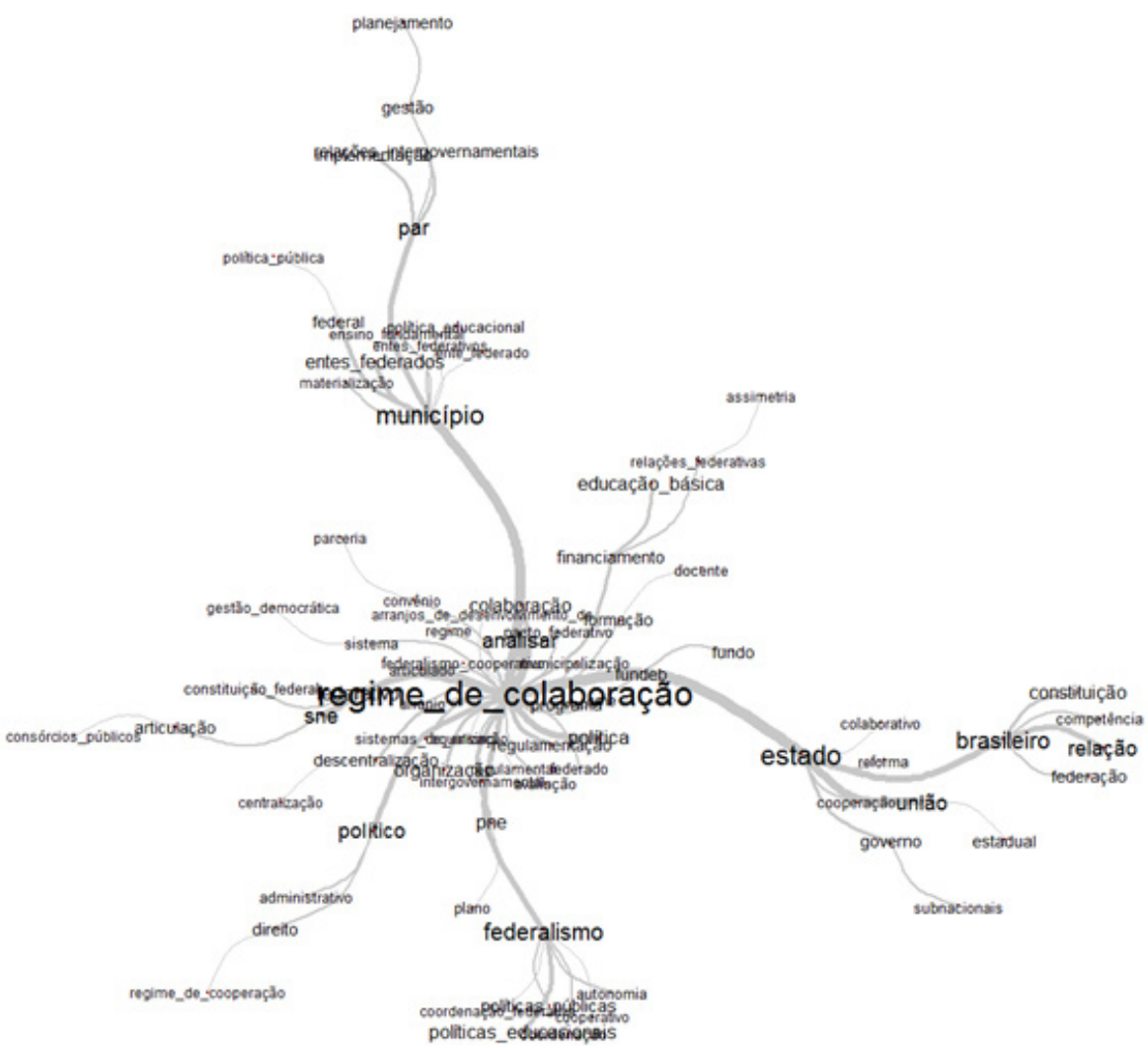

Fig. 1. Grafo Análise de Similitude - corpus artigos e anais ANPAE, 2019. 
Notam-se ainda, outras cinco palavras que mais se destacam: estado, município, federalismo, brasileiro e político. No centro da árvore está o Regime de Colaboração, com várias ramificações, além de estar circundado por algumas categorias, como: autonomia, centralização/descentralização, gestão democrática, sendo as principais: município e estado. Na ramificação "município", observamse as pesquisas sobre o PAR, referidas nas dimensões da gestão, implementação e do planejamento. Nessa ramificação, encontra-se a categoria relações intergovernamentais (RIG) sobreposta à da implementação.

A partir dessa caracterização, que considerou a correlação entre os objetos empíricos das pesquisas e os conceitos teóricos do federalismo, e com o auxílio do método de Reinert por meio da Classificação Hierárquica Descendente (CHD), a análise foi desenvolvida a partir de quatro categorias ${ }^{14}$. 1) Pesquisa, políticas e programas; 2) Financiamento e PNE; 3) A constituição do SNE e a regulamentação do Regime de Colaboração; 4) Federalismo, Direito à Educação e Descentralização. A primeira categoria foi subdividida em outra subcategoria - A implementação do PAR na efetivação do Regime de Colaboração - pelo fato de ter o maior índice de trabalhos.

14 O software processa o texto de modo que são identificadas classes de vocabulário, sendo assim, é possível inferir quais ideias o corpus textual deseja transmitir. A partir dessas classes, é feita a categorização temática para a análise de conteúdo dos textos. Portanto, a seleção das categorias se dá com base na recorrência maior apresentada no software. 


\section{1) Pesquisa, políticas e programas}

\section{Análise de Similitude - Pesquisas, políticas e programas}

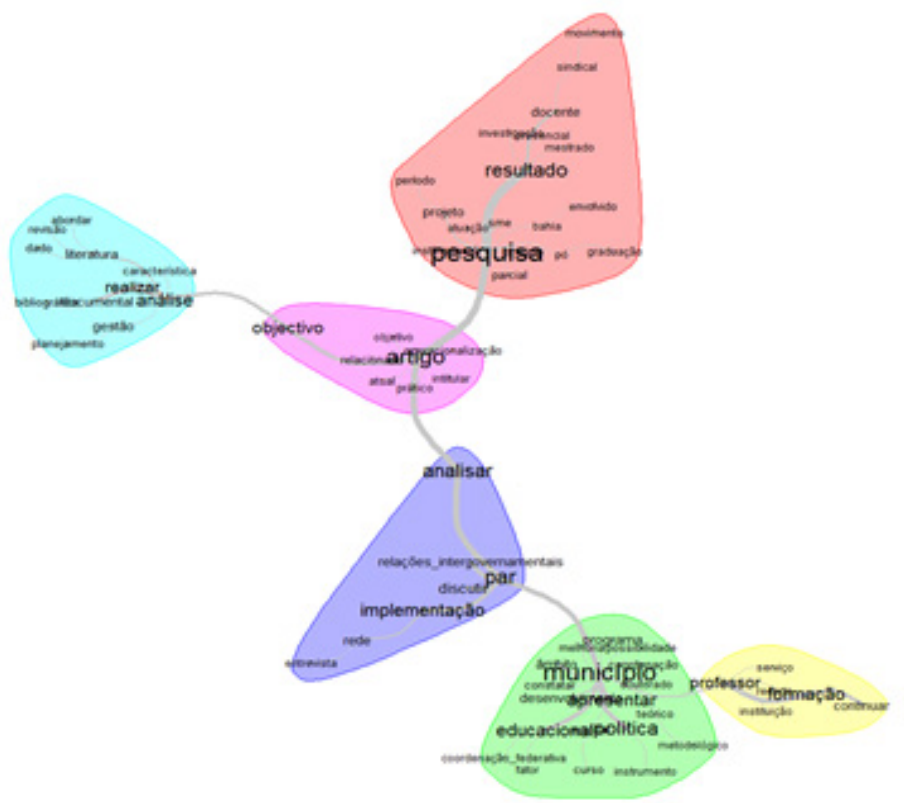

Fig 2. Grafo análise de similitude - categoria Pesquisa, políticas e programas

Essa categoria temática representa 31,9\% dos trabalhos, se comunicando com as demais por se tratar das metodologias empregadas nas pesquisas, bem como dos resultados informados nas publicações analisadas. Os estudos são desenvolvidos no âmbito dos programas de mestrado e/ou doutorado ou estão ligados à projetos de pesquisas mais abrangentes de grupos vinculados à pósgraduação. Há uma prevalência de estudos de natureza qualitativa, por meio de estudos de casos, análise bibliográfica e documental e também de entrevistas, sendo, portanto, pesquisas de natureza empírica. Além de representar o conjunto total dos textos examinados, essa categoria concentra um tipo e uma temática específica de pesquisa, visto que foi mais recorrente nas publicações, tornando possível a geração de outras subcategorias. A seguir, será examinada a subcategoria com maior presença. 


\section{1) A implementação do PAR na efetivação do Regime de Colaboração}

Os estudos sobre o PAR aparecem em 22 dos 82 trabalhos analisados, com destaque para estudos sobre sua implementação, em geral, via estudos de casos de municípios e estados, de modo a verificar a concretização do Regime de Colaboração. São também analisadas as Relações Intergovernamentais (RIG) entre os entes federativos, especialmente a relação com a União, com questionamentos sobre o PAR como instrumento de coordenação/colaboração federativa. A maioria dos estudos conclui pela existência de centralização do planejamento no governo federal.

Próximas a esta subcategoria, se encontram as pesquisas que abordam programas específicos, principalmente relacionados à formação docente, com destaque para o Programa Nacional de Formação de Professores da Educação Básica (Parfor) e os Fóruns Permanentes de Formação Continuada.

\section{2) Financiamento e PNE}

$\mathrm{Na}$ categoria financiamento e PNE, destacam-se os estudos sobre as políticas de fundos instituídas com vistas à equalização das disparidades entre os entes federativos no provimento da educação. Por isso, o debate vai transcorrer a partir do FUNDEF, do FUNDEB e de suas potencialidades. No contexto de aprovação do novo PNE, as disputas foram em torno da aprovação de metas e estratégias com maiores aportes de recursos para a educação, incluindo os recursos do pré-sal, bem como o estabelecimento do Custo Aluno Inicial (CAQi) que, de forma progressiva, chegaria ao Custo aluno Qualidade (CAQ). Essas indicações estão ainda para serem regulamentadas por meio de leis específicas, visto que não foram totalmente contempladas pela Lei 13.005/2014.

Além da dimensão mais focada na questão da distribuição dos recursos financeiros, outros estudos trataram dos espaços de negociação e participação política em vista da necessária construção e/ou fortalecimento de arenas de pactuação federativa, especialmente visando a fortalecer tanto a capacidade dos entes subnacionais no processo de negociação, quanto de ampliação do controle social dos gastos públicos. Essa categoria temática foi abordada por 14,5\% dos trabalhos. 


\section{Análise de similitude - Financiamento e PNE}

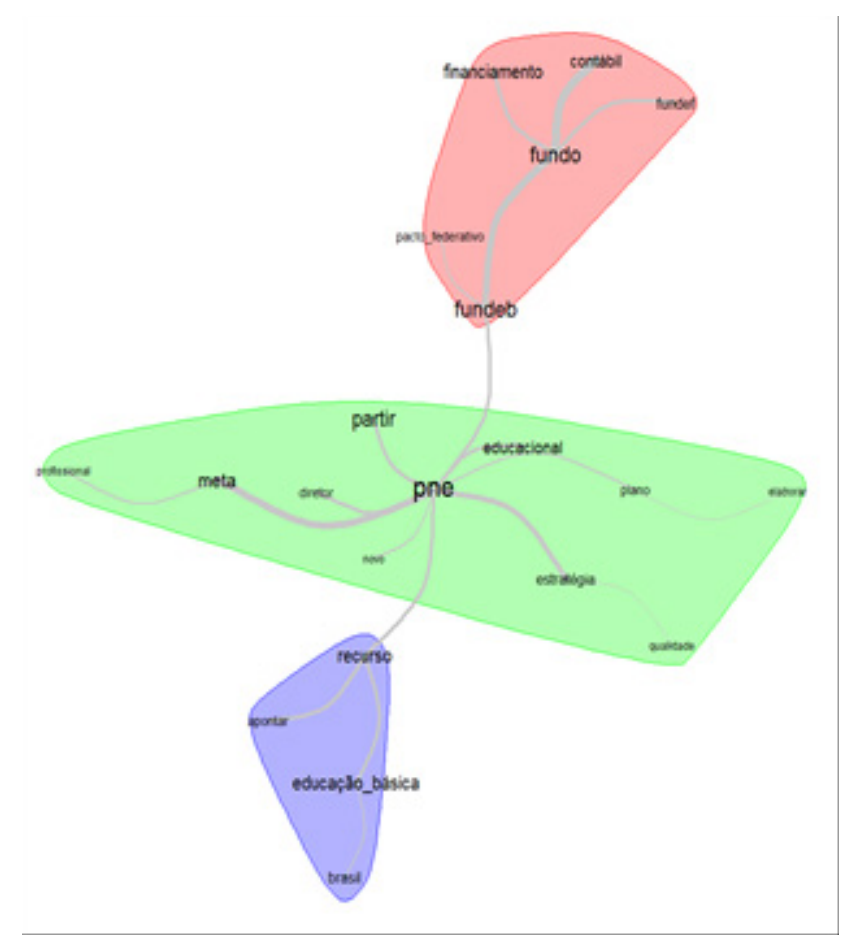

Fig. 3. Grafo Similitude, 2019.

\section{3) A constituição do SNE e a regulamentação do Regime de Colaboração}

Esta categoria representa $29,8 \%$ das produções. A constituição de um SNE foi o tema central das Conferências que debateram o novo PNE. No que tange à questão federativa, os estudos destacam a necessidade de uma articulação nacional, com importante papel coordenador e financiador da União. Historicamente, a educação brasileira foi se estruturando a partir de um conjunto desarticulado de redes de ensino. A LDB 9.394/96 não rompeu com essa estrutura e, ainda, ressaltou a autonomia dos sistemas educativos, sem a garantia da existência de um SNE, o que só veio a ser incluído na EC nº 59/2009.

A concepção de sistema mais recorrente nos estudos advém das contribuições de Saviani (2010), para quem o sistema é "o produto intencional e concreto de uma práxis intencional coletiva” (SAVIANI, 2010, p. 6). Entende-se que esta contribuição foi muito significativa, considerando que neste contexto, o conceito de sistema foi também compreendido a partir de outras perspectivas, 
principalmente influenciadas pelo paradigma da Nova Gestão Pública (NGP) ${ }^{15}$, onde o conceito de sistema é reduzido à ideia de estrutura. Nessa visão, os sistemas são tomados como arranjos institucionais que podem ser pensados dentro de uma racionalidade estritamente instrumental, portanto, voltada para a eficiência de seu funcionamento. As disputas no plano conceitual foram acompanhadas pelas querelas políticas em torno dos já propalados conflitos entre o público e o privado na conformação do sistema educacional brasileiro naquele período.

\section{Análise de Similitude - A constituição do SNE e a regulamentação do Regime de Colaboração}

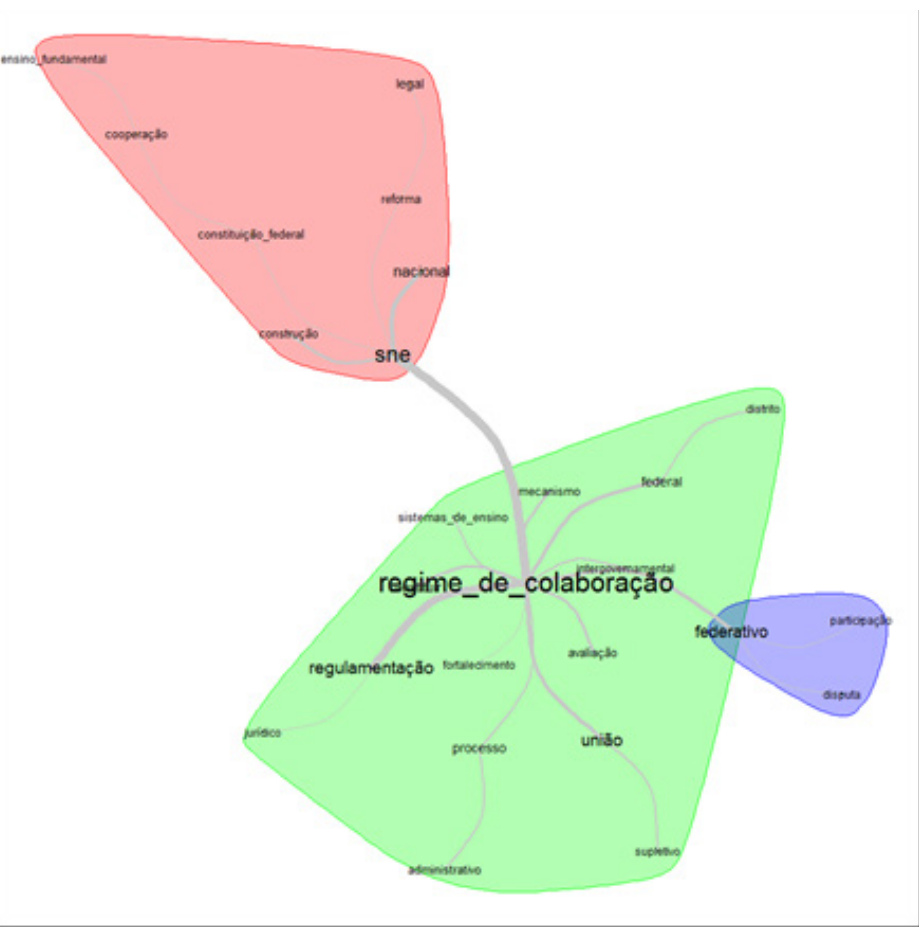

Fig. 4. Grafo Similitude, 2019.

\section{4) Federalismo, Direito à Educação e Descentralização}

Os trabalhos desta categoria temática representam $23,8 \%$ do total de trabalhos analisados. São, em geral, trabalhos de natureza teórica que apresentam maior nível de aprofundamento conceitual e de aproximação com o campo 
teórico do federalismo. Por isso, o termo federalismo aparece explicitado nos títulos e palavras-chave desses trabalhos.

Um aspecto que merece destaque nessa categoria e que pode ser visualizado na representação a seguir, diz respeito aos clusters "direito" e "federalismo". Historicamente, pode-se considerar que o direito à educação se constituiu em um subcampo do CAPE, principalmente caracterizado pelo enfoque jurídico-institucional. O grafo 5 mostra uma tendência de constituição de um novo subcampo - o federalismo educacional, cuja configuração se dará por meio da composição desse enfoque, mas também pela adesão de enfoques mais próximos do neoinstitucionalismo, muito em razão da influência de autores da ciência política. Essa influência foi constatada na análise das referências bibliográficas dominantes nos trabalhos. Todavia, também identificamos que os autores não explicitaram tal escolha. Nesse sentido, é possível afirmar ainda que, a tendência de estudos pluralistas (seja de teorização combinada ou adicionada), informada por Mainardes (2018), tende a se confirmar em nosso estudo.

\section{Análise Similitude. Federalismo, direito à educação e descentralização}

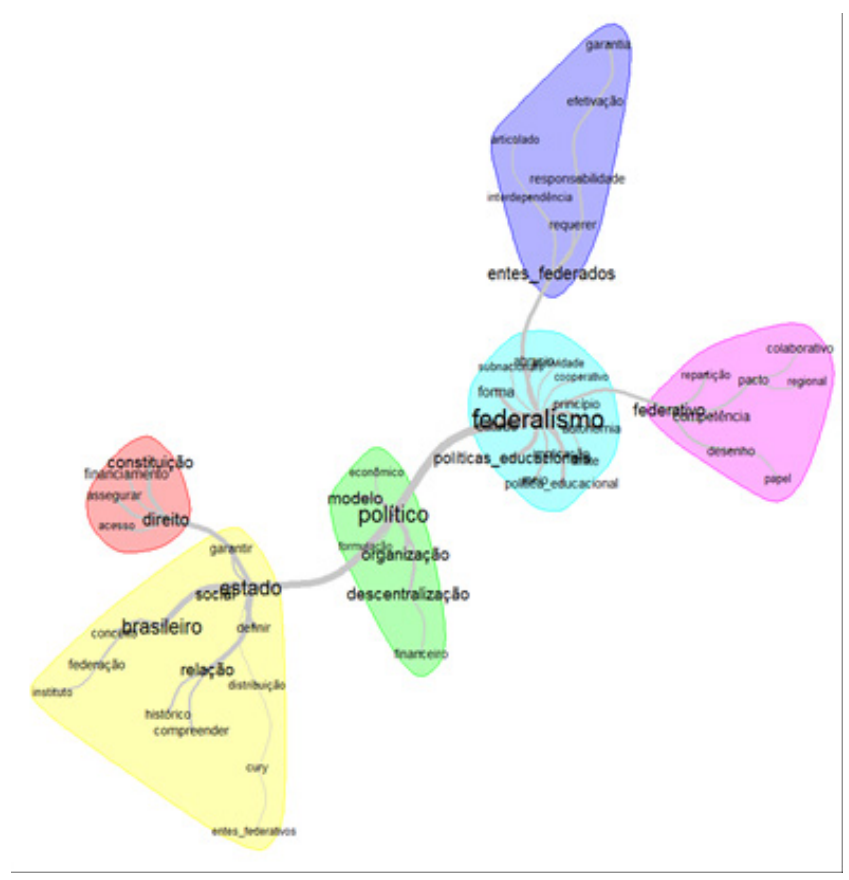

Fig 5. Grafo Similitude, 2019. 
Essa aproximação com o campo teórico do federalismo foi motivada também pelos novos desenhos e dispositivos constitucionais prescritos na CF/88. A inscrição da educação como direito social pela Constituição Federal é historicamente colocada à prova, visto que a Federação brasileira é cindida por profundas desigualdades regionais, econômicas, sociais e educacionais. No que tange ao provimento do direito à educação, a União vem relegando essa tarefa aos entes subnacionais, abstendo-se de sua responsabilidade, especialmente em relação à educação básica. No final dos anos de 1990, esse processo se aprofundou com a descentralização do ensino fundamental, via municipalização.

Assim, os estudos que vinham se concentrando na dimensão da gestão democrática pela via da descentralização e municipalização foram, em grande medida, redimensionados em razão da incursão de novos aportes teóricos, assim como pela implementação de "novas" políticas educacionais na últimas duas décadas.

\section{CONSIDERAÇÕES FINAIS}

O federalismo, para além de ser um fenômeno social e político característico da organização de alguns países, se configura em um campo teórico estratégico dos estudos sobre o processo de legitimação da ação do Estado e dos governos, com implicações no campo das políticas públicas e, em especial, das políticas educacionais. As análises dos trabalhos publicados nos anais dos eventos e artigos da RBPAE confirmam que a ANPAE participou ativamente do debate acadêmico do federalismo educacional, de forma a impulsionar o desenvolvimento de um subcampo.

Desde 2007, o total de 82 publicações da ANPAE pesquisadas utilizam os conceitos concernentes ao campo teórico do federalismo nas análises das políticas educacionais em seus mais variados objetos. Esta interrelação ocorreu nos mais diferentes graus de aprofundamento no que tange à apropriação teórica do federalismo. Os estudos empíricos são os mais recorrentes, principalmente aqueles voltados à análise da implementação de planos e programas $(31,9 \%)$. Se somados aos trabalhos sobre o financiamento $(14,5 \%)$, também caracterizados, em sua maioria, por estudos empíricos, representam quase $50 \%$ do total. Isso não significa afirmar que os demais estudos foram somente de natureza teórica.

Ressalta-se que, apesar de a maioria dos estudos analisados adotarem as relações intergovernamentais (RIG) como uma categoria relevante em suas análises, observa-se pouco aprofundamento sobre esse conceito. É importante ressaltar que o conceito de RIG vem sendo forjado no contexto da NGP como 
área de pesquisa acadêmica, sob o pressuposto de que os governos relacionam-se entre si, envolvendo múltiplas estruturas decisórias e arranjos multiorganizacionais, com destaque para os estudos organizacionais.

Grande parte das publicações da ANPAE assinalam para a defesa da regulamentação do Regime de Colaboração por meio de lei específica (como regulamentação do artigo 23 da CF/88). Além disso, há uma dominância no pressuposto de que a alteração da legislação, ao introduzir a expressão "formas de colaboração", abriu precedente para que mecanismos outros não formais e pouco sistemáticos fossem identificados como Regime de Colaboração, contribuindo para uma não clareza conceitual deste instituto jurídico. Para a maioria das publicações, essa forma de compreender o Regime de Colaboração vem ainda possibilitando o estabelecimento de parcerias entre fundações privadas e segmentos empresariais com o poder público, como forma de apropriação dos recursos públicos. Portanto, esses trabalhos advogam pela necessária distinção conceitual entre os termos.

Por outro lado, alguns trabalhos consideraram que o Regime de Colaboração vem se materializando por meio de políticas como o FUNDEB, o PDE e o PAR, apesar de avaliarem que seus efeitos foram muito discretos e que ainda se traduzem de forma muito verticalizada e centralizada.

Podemos afirmar que a ANPAE constituiu um habitus no CAPE de estudos do federalismo educacional, de forma a adquirir um capital científico. Ou seja, a ANPAE construiu uma posição de domínio do conhecimento sobre o federalismo educacional com reconhecimento acadêmico e político que faz crer, com base na centralidade do tema, que contribuiu para a criação de um subcampo.

\section{REFERENNCIAS}

AFFONSO, R; SILVA, P.. A federação em perspectiva. São Paulo: Fundap, 1995. p. 54-60. Buenos Aires: Miño y Dávila Editores, 1995.

ALMEIDA, M. H. T. Federalismo, democracia e governo no Brasil: idéias, hipóteses e evidências. BIB: Revista Brasileira de Informação Bibliográfica em Ciências Sociais, n. 51, p. 13-34, 2001.

AVRITZER, L; MILANI, C.R.S.; BRAGA, M. S., (ORGs). A Ciência Política no Brasil (1960-2015). Rio de Janeiro: FGV Editora, 2016.

BARDIN, L. Análise de conteúdo. São Paulo: Edições, 2011. 
BOAVENTURA, E. M. Os Sistemas Municipais de Educação. RBE, V. 9, N. 2 , 1993, p 49-68.

BOURDIEU, P. Meditações pascalianas I. Pierre Bourdieu; tradução Sergio Miceli. Rio de Janeiro: Bertrand Brasil. 2001.

BOURDIEU, P. O poder simbólico. Tradução de Fernando Tomaz. Rio de Janeiro: Bertrand Brasil, 1989.

BOURDIEU, P. Os usos sociais da ciência - Por uma sociologia clínica do campo científico . São Paulo: Unesp, 2004.

BRASIL, Lei 13.005 de 25 de junho de 2014. Aprova o Plano Nacional de Educação - PNE e dá outras providências. Diário Oficial da União, Brasília, DF, 26 jun. 2014.

BRASIL. Lei no 9.394, de 20 de dezembro de 1996. Lei de Diretrizes e Bases da Educação Nacional. Diário Oficial da União, Brasília, DF, 24 dez. 1996. Disponível em: http://www.planalto.gov.br/ccivil_03/Leis/L9394.htm. Acesso em: 08 abr. 2010.

FERREIRA, E. B. Federalismo e planejamento educacional no exercício do PAR. Cadernos de Pesquisa, v. 44, n. 153, p. 602-623, 2014.

KRAWCZYK, N. A historicidade da pesquisa em política educacional: o caso do Brasil. Jornal de Políticas Educacionais, Curitiba, v. 6, n. 12, p. 3-11, jul./dez. 2012.

LOTTA, G. Federalismo e políticas públicas: abrangências e convergências temáticas desse campo de estudos no Brasil. História, Ciências, Saúde Manguinhos, Rio de Janeiro, v.22, n.3, jul.-set, p.1092-1096. 2015.

MAINARDES, J. A pesquisa no campo da política educacional: perspectivas teórico-epistemológicas e o lugar do pluralismo. RBE, p. 1-20, v. 23, 2018.

OLIVEIRA, D. A. As políticas públicas em educação e a pesquisa acadêmica. In: DUARTE, Adriana; OLIVEIRA, Dalila Andrade (Orgs.). Políticas públicas e educação: regulação e conhecimento. Belo Horizonte: Fino Traço (Edvcere, 9), 2011. p. 71-89. 
OLIVEIRA, L.F.R. de. Tutorial (básico) de utilização do Iramuteq. [Goiânia]: Universidade

POCHMANN, M. Estado e capitalismo no Brasil: a inflexão atual no padrão das políticas públicas do ciclo político da nova república. Educação \& Sociedade, v. 38, n. 139, 2017.p. 309-330.

SANDER, B. Centralização e descentralização na Administração da Educação na América Latina. RBAE, v. 6, n. 1, 1988, p. 53-54.

SAVIANI, D. Sistema Nacional de Educação articulado ao Plano Nacional de Educação. RBE, v. 15 n. 44 maio/ago. 2010.

SILVA, A.A.; JACOMINI, M.A. Pesquisa em políticas educacionais: características e tendências. Feira de Santana: UEFS Editora, 2016.

SOARES, S.T. Política educacional na pós-graduação em Educação: uma análise a partir da trajetória coletiva dos pesquisadores. 2019. Tese (Doutorado em Educação) - Universidade Estadual de Ponta Grossa, Ponta Grossa, 2019.

SOUZA, A. R. A pesquisa em políticas educacionais no Brasil: de que estamos tratando? Práxis Educativa, Ponta Grossa, v. 9, n. 2, p. 355-367, jul./dez. 2014.

SOUZA, C. Federalismo: teorias e conceitos revisitados. Revista Brasileira de Informação Bibliográfica em Ciências Sociais, v. 65, p. 27-48, 2008.

SOUZA, C. Políticas públicas: uma revisão de literatura. Sociologias, Porto Alegre, v. 8, n. 16, p. 20-45, jul./dez. 2006.

STREMEL, S. A constituição do campo acadêmico da política educacional no Brasil. Ponta Grossa. Tese (Doutorado em Educação) - Programa de PósGraduação em Educação, Universidade Estadual de Ponta Grossa, Ponta Grossa. 2016.315f.

SUDANO, A. C. P; SOARES, A. G., VERGILLI, G. E. O Debate sobre a Pesquisa em Políticas Públicas no Brasil a partir da análise dos trabalhos apresentados na ANPOCS: evolução e desafios. In: XXXIX Encontro Anual da ANPOCS. Caxambu, Anpocs. 2015. 
TELLO, C. 2019. Notas Históricas y Epistemológicas sobre el Campo de la Política Educativa en Latinoamérica. Educação \& Sociedade, v. 40, 2019.

\section{Eliza Bartolozzi Ferreira}

Doutora em Educação pela Universidade Federal de Minas Gerais

Professora Associada do Departamento de Educação, Política e Sociedade do Centro de Educação da Universidade Federal do Espírito Santo. E-mail: eliza. bartolozzi@gmail.com

\section{Andreza Alves Ferreira}

Doutoranda em Educação no Programa de Pós Graduação da Universidade Federal do Espírito Santo. E-mail: alvesferreiraandreza@gmail.com

Recebido em 06/01/2020

Aprovado em 15/06/2020 